Sains Malaysiana 49(7)(2020): 1755-1764

http://dx.doi.org/10.17576/jsm-2020-4907-25

\title{
Suatu Kelas Kaedah Optimum Bak Steffensen Bebas Terbitan untuk Punca Berganda
}

(A Class of Steffensen-Like Optimal Derivative-Free Method for Multiple Roots)

\author{
SYAHMI AFANDI SARIMAN \& ISHAK HASHIM*
}

\begin{abstract}
ABSTRAK
Objektif utama makalah ini adalah untuk mencari punca berganda bagi persamaan tak linear. Kaedah lelaran tiga tahap diubah suai menjadi bebas terbitan yang mengekalkan peringkat penumpuan optimum lapan. Skema lelaran bebas terbitan dibangunkan berdasarkan kaedah bak Steffensen dan konsep beza terhingga. Kaedah yang diubah suai ini selaras dengan penumpuan optimum mengikut konjektur Kung Traub yang dibuktikan melalui analisis penumpuan. Skema lelaran ini dapat bersaing dengan kaedah lelaran sedia ada daripada segi kebebasan terbitan. Indeks keberkesanan telah mencapai nilai $E=1.682$ dan lebih baik daripada kaedah Newton klasik, E = 1.414. Beberapa ujian berangka dilakukan dalam menentukan keberkesanan skema lelaran yang dibangunkan bagi mencari punca berganda mahupun punca mudah.
\end{abstract}

Kata kunci: Bebas terbitan; kaedah lelaran; penumpuan optimum; persamaan tak linear; punca berganda

\section{ABSTRACT}

The main objective of this paper was to find multiple roots for nonlinear equations. The three-step iteration method is modified to be derivative free which maintains an optimum convergence of eight. The derivative-free iteration scheme was developed based on the Steffensen-like method and finite difference concept. The modified method satisfies the optimal convergence of Kung-Traub's conjectures as shown in the convergence analysis. The iteration scheme can compete with the existing iteration methods in terms of free derivatives. The efficiency index has reached the value $E=1.682$ and is better than the classical Newton method, $E=1.414$. Numerical experiments have been done to determine the effectiveness of the iteration scheme in finding multiple roots and also simple roots.

Keywords: Derivative-free; iterative method; multiple roots; nonlinear equation; optimal convergence

\section{PENGENALAN}

Penyelesaian persamaan tak linear $f(x)=0$ adalah antara topik yang popular dikaji oleh penyelidik matematik kini. Bahkan bidang ini merupakan bidang yang penting dalam menyelesaikan pelbagai masalah aplikasi yang melibatkan fizik dan kimia. Walau bagaimanapun, menyelesaikan persamaan dengan menggunakan kaedah beranalisis menjadi satu kekangan apabila berhadapan dengan fungsi yang rumit. Maka, kaedah berangka digunakan dalam mencari penganggaran punca bagi suatu fungsi tersebut.

Kaedah Newton merupakan kaedah popular yang digunakan dalam mencari punca persamaan tak linear. Schröder (1870) telah menggunakan suatu pendekatan fungsi,

$$
F(x)=f^{\frac{1}{m}}(x)
$$

yang mengubah kaedah Newton klasik dalam mencari punca mudah kepada punca berganda.

$$
x_{n+1}=x_{n}-m \cdot \frac{f(x)}{f^{\prime}(x)}
$$

yang $m$ merupakan nilai kegandaan punca bagi suatu fungsi. Kebelakangan ini, ramai penyelidik meneruskan dalam mencari punca berganda bagi persamaan tak linear (Behl et al. 2019a; Parvaneh \& Ghanbari 2017; Petković \& Petković 2019; Zafar et al. 2018). Kebanyakan skema lelaran yang dibangunkan telah mencapai peringkat penumpuan lapan tetapi masih mempunyai terbitan pada skema lelaran tersebut.

Steffensen (1933) telah membangunkan satu skema lelaran yang bebas daripada sebarang terbitan pertama pada kaedah Newton Klasik,

$$
\left\{\begin{array}{l}
y_{n}=x_{n}+f\left(x_{n}\right) \\
x_{n+1}=x_{n}-\frac{f\left(x_{n}\right)}{f\left[y_{n}, x_{n}\right]}
\end{array}\right.
$$

kaedah ini menggunakan konsep beza terbahagi dalam mengganggar terbitan pertama fungsi $f(x)$, 


$$
f^{\prime}\left(x_{n}\right) \approx f\left[y_{n}, x_{n}\right]=\frac{f\left(y_{n}\right)-f\left(x_{n}\right)}{y_{n}-x_{n}}
$$

dan kaedah tersebut telah mencapai peringkat penumpuan kuadratik. Kajian ini diteruskan oleh Cordero et al. (2013) dengan membangunkan satu skema lelaran peringkat empat bebas daripada terbitan pertama dengan menggunakan kaedah Steffensen dan penganggaran Padé. Cordero dan Torregrosa (2016) telah membangunkan kaedah lelaran umum dalam mencari punca mudah dan punca berganda dengan ketiadaan sebarang terbitan. Kini, ramai para penyelidik mengkaji mengenai kebebasan terbitan dalam skema lelaran yang ingin dibangunkan (Behl et al. 2019b; Junjua et al. 2019; Li et al. 2019; Tao \& Madhu 2019). Tetapi ramai para pengkaji lebih tertumpu kepada mencipta lelaran yang bebas terbitan bagi mencari punca mudah sahaja.

Sharma et al. (2019) telah membangunkan skema lelaran bak Traub-Steffensen dalam mencari punca berganda. Skema lelaran tiga tahap bebas terbitan ini telah mencapai peringkat penumpuan tujuh. Berikut merupakan salah satu skema lelaran yang dibangunkan:

$$
\left\{\begin{array}{c}
y_{n}=x_{n}-m \frac{f\left(x_{n}\right)}{f\left[x_{n}, t_{n}\right]} \\
z_{n}=y_{n}-m u\left(\frac{1+u}{1-u+3 u^{2}}\right) \frac{f\left(x_{n}\right)}{f\left[x_{n}, t_{n}\right]} \\
x_{n+1}=z_{n}-m v\left(2 u+\frac{1}{1-w}\right) \frac{f\left(x_{n}\right)}{f\left[x_{n}, t_{n}\right]}
\end{array}\right.
$$

yang $u=\left(\frac{f\left(y_{n}\right)}{f\left(x_{n}\right)}\right)^{\frac{1}{m}}, v=\left(\frac{f\left(z_{n}\right)}{f\left(x_{n}\right)}\right)^{\frac{1}{m}}, \quad w=\left(\frac{f\left(z_{n}\right)}{f\left(y_{n}\right)}\right)^{\frac{1}{m}} \mathrm{dan}$ $t_{n}=x_{n}+f\left(x_{n}\right)$.

Konjektur Kung-Traub telah mengatakan bahawa peringkat penumpuan bagi suatu kaedah lelaran multititik optimal $2^{n-1}$ apabila bilangan penilaian fungsi dan terbitan mempunyai $n$ fungsi (Kung \& Traub 1974). Keberkesanan bagi suatu kaedah lelaran dapat diukur dengan menggunakan Indeks Keberkesanan yang diperkenalkan oleh Ostrowski (1966), iaitu

$$
E=P^{\frac{1}{m}}
$$

yang $P$ merupakan peringkat penumpuan kaedah lelaran dan $m$ merupakan bilangan penilaian fungsi bagi suatu tahap dalam kaedah lelaran tersebut.

Dalam kajian ini, kaedah yang diperkenalkan mencapai peringkat penumpuan optimum dan bebas daripada sebarang terbitan. Skema lelaran yang dibangunkan oleh Akram et al. (2019) dengan peringkat penumpuan optimum lapan akan diubah suai dengan menghapuskan terbitan pertama menggunakan kaedah bak Steffensen dan konsep beza terhingga.

\section{KAEDAH}

KAEDAH LELARAN TERUBAH SUAI

Pertimbangkan skema lelaran yang dibangunkan oleh Akram et al. (2019):

$$
\begin{gathered}
w_{n}=x_{n}-m \cdot \frac{f\left(x_{n}\right)}{f^{\prime}\left(x_{n}\right)}, n \geq 0, \\
y_{n}=w_{n}-m \cdot t \cdot H(t) \cdot \frac{f\left(x_{n}\right)}{f^{\prime}\left(x_{n}\right)}, \\
x_{n+1}=y_{n}-m \cdot t \cdot L(s, u) \cdot \frac{f\left(x_{n}\right)}{f^{\prime}\left(x_{n}\right)}, \\
\text { yang } t=\sqrt[m]{\frac{f\left(w_{n}\right)}{f\left(x_{n}\right)}}, s=\sqrt[m]{\frac{f\left(y_{n}\right)}{f\left(w_{n}\right)}}, \mathbf{u}=\sqrt[m]{\frac{f\left(y_{n}\right)}{f\left(x_{n}\right)}}
\end{gathered}
$$

yang fungsi $H: \mathbb{C} \rightarrow \mathbb{C}$ dihadkan pada fungsi analitik pada rantau yang berdekatan 0 dan fungsi pemberat $L: \mathbb{C}^{2} \rightarrow \mathbb{C}$ ialah fungsi holomorfi pada rantau berdekatan $(0,0) . t$, $s$ dan $u$ merupakan satu ke nilai gandaan fungsi.

Dalam kajian ini, kami akan menganggar terbitan pertama seperti berikut (Cordero \& Torregrosa 2015):

$f^{\prime}\left(x_{n}\right) \approx f\left[x_{n}, z_{n}\right], z_{n}=x_{n}+\lambda f\left(x_{n}\right)^{k}, \lambda=\mathbb{R}-\{0\}, k \geq q-1$

yang $\lambda$ merupakan sebarang nilai nyata kecuali sifar dan $q$ merupakan bilangan penilaian fungsi bagi satu lelaran yang dibangunkan. Dengan empat penilaian fungsi pada persamaan (7) iaitu $q=4$, maka nilai $k \geq 3$. Oleh itu, dengan mengambil nilai $k=3$, maka kaedah lelaran terubah suai adalah seperti berikut:

$$
\begin{gathered}
w_{n}=x_{n}-m \cdot \frac{f\left(x_{n}\right)}{f\left[x_{n}, z_{n}\right]}, n \geq 0, \\
y_{n}=w_{n}-m \cdot t \cdot H(t) \cdot \frac{f\left(x_{n}\right)}{f\left[x_{n}, z_{n}\right]}, \\
x_{n+1}=y_{n}-m \cdot t \cdot L(s, u) \cdot \frac{f\left(x_{n}\right)}{f\left[x_{n}, z_{n}\right]},
\end{gathered}
$$

$$
\begin{aligned}
\text { yang } t & =\sqrt[m]{\frac{f\left(w_{n}\right)}{f\left(x_{n}\right)}}, s=\sqrt[m]{\frac{f\left(y_{n}\right)}{f\left(w_{n}\right)}}, \mathrm{u}=\sqrt[m]{\frac{f\left(y_{n}\right)}{f\left(x_{n}\right)}}, f\left[x_{n}, z_{n}\right] \\
& =f\left[x_{n}, x_{n}+\lambda\left(f\left(x_{n}\right)\right)^{3}\right]
\end{aligned}
$$

\section{ANALISIS PENUMPUAN}

Dalam bahagian ini, kami akan membuktikan analisis penumpuan berdasarkan kaedah yang dicadangkan oleh Akram et al. (2019) dan pengubahsuaian kepada terbitan pertama kaedah tersebut dengan bantuan perisian Mathematica 12. 
Teorem 1 Andaikan $x=\alpha$ merupakan punca berganda yang mempunyai gandaan $m \geq 1$ pada fungsi analitik $f: \quad \mathbb{C} \rightarrow \mathbb{C}$ dalam rantau berdekatan dengan punca berganda $\alpha$ bagi $f(x)$. Skema lelaran (9) akan menumpu pada peringkat lapan sekiranya syarat berikut dipenuhi:

$$
\begin{aligned}
H_{0}= & 1, H_{1}=2, H_{2}=-2, H_{3}=36, L_{00}=0, L_{10}=1, L_{01} \\
& =2, L_{11}=4, L_{20}=2
\end{aligned}
$$

Maka, persamaan ralat akan diperoleh jika syarat persamaan (10) dipenuhi:

$e_{n+1}=\frac{1}{24 m^{7}}\left[c_{1}\left(c_{1}^{2}(11+m)-2 m c_{2}\right)\left(\left(677+108 m+7 m^{2}\right) c_{1}^{4}-24 m(9+m) c_{1}^{2} c_{2}\right.\right.$

$$
\left.\left.+12 m^{2} c_{2}^{2}+12 m^{2} c_{1} c_{3}\right)\right] e_{n}^{8}+O\left(e_{n}^{9}\right)
$$

Bukti Andaikan $x=\alpha$ merupakan punca ganda bagi $f(x)$. Kembangkan fungsi $f\left(x_{n}\right)$ dengan menggunakan perkembangan siri Taylor pada $x=\alpha$, maka kita akan peroleh

$$
\begin{aligned}
f\left(x_{n}\right)= & \frac{f^{m}(\alpha)}{m !} e_{n}^{m}+c_{1} \frac{f^{m}(\alpha)}{m !} e_{n}^{m+1}+c_{2} \frac{f^{m}(\alpha)}{m !} e_{n}^{m+2}+c_{3} \frac{f^{m}(\alpha)}{m !} e_{n}^{m+3}+c_{4} \frac{f^{m}(\alpha)}{m !} e_{n}^{m+4} \\
& +c_{5} \frac{f^{m}(\alpha)}{m !} e_{n}^{m+5}+c_{6} \frac{f^{m}(\alpha)}{m !} e_{n}^{m+6}+c_{7} \frac{f^{m}(\alpha)}{m !} e_{n}^{m+7}+c_{8} \frac{f^{m}(\alpha)}{m !} e_{n}^{m+8}+O\left(e_{n}^{9}\right)
\end{aligned}
$$

ataupun boleh ditulis sebagai

$f\left(x_{n}\right)=\frac{f^{m}(\alpha)}{m !} e_{n}^{m}\left(1+c_{1} e_{n}+c_{2} e_{n}^{2}+c_{3} e_{n}^{3}+c_{4} e_{n}^{4}+c_{5} e_{n}^{5}+c_{6} e_{n}^{6}+c_{7} e_{n}^{7}+c_{8} e_{n}^{8}+O\left(e_{n}^{9}\right)\right)$

yang $e_{n}=x_{n}-\alpha$ dan $c_{i}=\frac{m !}{(m+i) !} \frac{f^{(m+k)}(\alpha)}{f^{(m)}(\alpha)}, i=1,2,3, \ldots$. Dengan menggantikan persamaan (13) ke dalam persamaan (8) dengan mengambil $\lambda=1$ dan $k=3$, kita akan memperoleh,

$$
\begin{aligned}
z_{n}-\alpha & =e_{n}+\left(\frac{f^{(m)}(\alpha)}{m !}\right)^{3} e_{n}^{3 m} \\
& \left(1+c_{1} e_{n}+c_{2} e_{n}^{2}+c_{3} e_{n}^{3}+c_{4} e_{n}^{4}+c_{5} e_{n}^{5}+c_{6} e_{n}^{6}+c_{7} e_{n}^{7}+c_{8} e_{n}^{8}+O\left(e_{n}^{9}\right)\right)^{3}
\end{aligned}
$$

Dengan menggunakan siri Taylor pada $\alpha$, maka

$$
\begin{aligned}
f\left(z_{n}\right)= & \frac{f^{(m)}(\alpha)}{m !}\left(z_{n}-\alpha\right)^{m}\left(1+c_{1}\left(z_{n}-\alpha\right)+c_{2}\left(z_{n}-\alpha\right)^{2}+c_{3}\left(z_{n}-\alpha\right)^{3}+c_{4}\left(z_{n}-\alpha\right)^{4}\right. \\
& \left.+c_{5}\left(z_{n}-\alpha\right)^{5}+c_{6}\left(z_{n}-\alpha\right)^{6}+c_{7}\left(z_{n}-\alpha\right)^{7}+c_{8}\left(z_{n}-\alpha\right)^{8}+O\left(e_{n}^{9}\right)\right)
\end{aligned}
$$

Gantikan persamaan (13) sehingga persamaan (15) pada tahap pertama bagi skema lelaran persamaan (9), maka

$$
w_{n}-\alpha=\frac{c_{1}}{m} e_{n}^{2}+\frac{2 m c_{2}-(m+1) c_{1}^{2}}{m^{2}} e_{n}^{3}+\sum_{k=0}^{4} H_{k} e_{n}^{k+4}+O\left(e_{n}^{9}\right)
$$

yang $H_{k}=H_{k}\left(m, c_{1}, c_{2}, c_{3}, \ldots, c_{8}\right)$ dalam sebutan $\left(m, c_{1}, c_{2}, c_{3}, \ldots, c_{8}\right)$. Selepas melakukan kembangan siri Taylor pada persamaan (16), kami mendapat $f\left(w_{n}\right)=\frac{f^{(m)}(\alpha)}{m !} e_{n}^{2 m}\left(\frac{\left(\frac{c_{1}}{m}\right)^{m}}{m !}+\frac{2 c_{2} m-c_{1}^{2}(m+1)}{c_{1} m !}\left(\frac{c_{1}}{m}\right) e_{n}+\sum_{k=0}^{6} \gamma_{k} e_{n}^{k+2}+O\left(e_{n}^{9}\right)\right)$

Dengan menggunakan persamaan (13) dan persamaan (17), maka

$$
t=\frac{c_{1}}{m} e_{n}+\frac{2 c_{2} m-c_{1}^{2}(m+1)}{m^{2}} e_{n}^{2}+\omega_{1} e_{n}^{3}+\omega_{2} e_{n}^{4}+\omega_{3} e_{n}^{5}+O\left(e_{n}^{6}\right)
$$

yang $\omega_{1}=\frac{1}{2 m^{3}}\left[c_{1}^{3}\left(2 m^{2}+7 m+7\right)+6 c_{3} m^{2}-2 c_{1} c_{2} m(3 m+7)\right], \omega_{2}=-\frac{1}{6 m^{4}}\left[c_{1}^{4}\left(6 m^{3}+29 m^{2}+51 m+34\right)\right.$

$\left.-6 c_{2} c_{1}^{2} m\left(4 m^{2}+16 m+17\right)+12 c_{1} c_{3} m^{2}(2 m+5)+12 m^{2}\left(c_{2}^{2}(m+3)-2 c_{4} m\right)\right], \omega_{3}=\frac{1}{24 m^{5}}$ $\left[-24 m^{3}\left(c_{2} c_{3}(5 m+17)-5 c_{5} m\right)+12 c_{3} c_{1}^{2} m^{2}\left(10 m^{2}+43 m+49\right)+12 c_{1} m^{2}\left(c_{2}^{2}\left(10 m^{2}+47 m+53\right)\right.\right.$ $\left.\left.-2 c_{4} m(5 m+13)\right)-4 c_{2} c_{1}^{3} m\left(30 m^{3}+163 m^{2}+306 m+209\right)+c_{1}^{5}\left(24 m^{4}+146 m^{3}+355 m^{2}+418 m+209\right)\right]$.

$H(t)$ boleh ditulis dalam bentuk siri Taylor seperti berikut:

$$
H(t)=H_{0}+H_{1} t+\frac{H_{2}}{2} t^{2}+\frac{H_{3}}{6} t^{3}+O\left(e_{n}^{4}\right)
$$

Gantikan persamaan (16) sehingga persamaan (19) ke dalam tahap kedua pada persamaan skema lelaran (9) dan akan memperoleh

$$
\begin{aligned}
y_{n}-\alpha= & \frac{-\left(-1+H_{0}\right) c_{1}}{m} e_{n}^{2}-\frac{\left(\left(1+H_{1}+m-H_{0}(3+m)\right) c_{1}^{2}+2\left(-1+H_{0}\right) m c_{2}\right)}{m^{2}} e_{n}^{3} \\
& +\frac{1}{2 m^{3}}\left[\left(2+10 H_{1}-H_{2}+4 m+4 H_{1} m+2 m^{2}-H_{0}\left(13+11 m+2 m^{2}\right)\right) c_{1}^{3}\right. \\
& \left.+2 m\left(\left(-4-4 H_{1}-3 m+H_{0}(11+3 m)\right) c_{1} c_{2}-6\left(-1+H_{0}\right) m^{2} c_{3}\right)\right] e_{n}^{4}+a_{5} e_{n}^{5} \\
& +a_{6} e_{n}^{6}+a_{7} e_{n}^{7}+O\left(e_{n}^{8}\right)
\end{aligned}
$$

Dengan memilih nilai $H_{0}=1$ dan $H_{1}=2$, kita akan memperoleh

$$
y_{n}-\alpha=\frac{c_{1}\left(-2 m c_{2}+c_{1}^{2}\left(9+m-H_{2}\right)\right)}{2 m^{3}} e_{n}^{4}+a_{5} e_{n}^{5}+a_{6} e_{n}^{6}+a_{7} e_{n}^{7}+O\left(e_{n}^{8}\right)
$$

yang $a_{5}=-\frac{1}{6 m^{4}}\left[c_{1}^{4}\left(125+H_{3}+84 m+7 m^{2}-3 H_{2}(7+3 m)+6 m\left(-3 H_{2}+4(7+m)\right) c_{1}^{2} c_{2}+12 c_{2}^{2} m^{2}+12 c_{2} c_{1} m\right)\right]$, $a_{6}=\frac{1}{24 m^{n}}\left[1507+1850 m+677 m^{2}+46 m^{3}+4 H_{3}(9+4 m)-6 H_{2}\left(59+53 m+12 m^{2}\right) c_{1}^{5}-4 m(925\right.$ $+8 H_{3}+594 m+53 m^{2}-3 H_{2}(53+21 m) c_{1}^{3} c_{2}+12 m^{2}\left(83-9 H_{2}+13 m\right) c_{1}^{2} c_{3}-168 m^{3} c_{2} c_{3}$ $\left.12 m^{2} c_{1}\left(115-12 H_{2}+17 m\right) c_{2}^{2}-6 m c_{4}\right]_{\operatorname{dan}} a_{7}=-\left[12 c_{1}^{2} c_{3} m^{2}(36 \beta+13 m+11)+\left(37-168 c_{2} c_{3} m^{3}+\right.\right.$ $\left.4 c_{1}^{3} c_{2} m\left(96 \beta^{2}+252 \beta+53 m^{2}+18(14 \beta+5) m\right)+12 c_{1} m^{2}\left(c_{2}^{2}(48 \beta+17 m+19)-6 c_{4} m\right)\right]$.

Dengan melakukan kembangan siri Taylor pada persamaan (21), kita akan mendapati bahawa

$$
\begin{aligned}
& f\left(y_{n}\right)=f^{(m)}(\alpha) e_{n}^{4 m}\left(\frac{2^{-m} m^{-3 m} c_{1}^{m}\left(-2 m c_{2}+c_{1}^{2}\left(9+m-H_{2}\right)\right)^{m}}{m !}-\frac{1}{3 m !}(22)\right. \\
& \left.\left(2^{-m} m^{-3 m} c_{1}^{m-1}\left(-2 m c_{2}+c_{1}^{2}\left(9+m-H_{2}\right)\right)^{m-1} \eta_{0}\right) e_{n}+\sum_{k=0}^{7} \omega_{k} e_{n}^{k+1}+O\left(e_{n}^{9}\right)\right) \\
& \text { yang } \eta_{0}=12 m^{2} c_{2}^{2}+12 m^{2} c_{1} c_{3}-6 m c_{1}^{2} c_{2}\left(4(7+m)-3 H_{2}\right)+c_{1}^{4}(125+7 m \\
& \left.(12+m)-3(7+3 m) H_{2}+H_{3}\right) .
\end{aligned}
$$


Dengan menggantikan persamaan (17) dan persamaan (22), kita akan mendapati

$$
s=\frac{c_{1}^{2}\left(9-H_{2}+m\right)-2 m c_{2}}{2 m^{2}} e_{n}^{2}+\eta_{1} e_{n}^{3}+\eta_{2} e_{n}^{4}+\eta_{3} e_{n}^{5}+O\left(e_{n}^{6}\right)
$$

yang $\eta_{1}=-\frac{1}{6 m^{3}}\left[c_{1}^{3}\left(98+H_{3}+4 m^{2}+54 m-6 H_{2}(3+m)-12 m\left(9-H_{2}+m\right) c_{1} c_{2}+12 m^{2} c_{3}\right)\right]$, $\eta_{2}=\frac{1}{24 m^{4}}\left[899+1002 m+313 m^{2}+18 m^{3}+4 H_{3}(8+3 m)-6 H_{2}\left(43+33 m+6 m^{2}\right) c_{1}^{4}-\right.$ $12 m\left(167+2 H_{3}+87 m+6 m^{2}-H_{2}(33+10 m)\right) c_{1}^{2} c_{2}+24 m^{2}\left(26-3 H_{2}+3 m\right) c_{1} c_{3}+$ $\left.12 m^{2}\left(c_{2}^{2}\left(35-4 H_{2}+3 m\right)-6 m c_{4}\right)\right]$ dan $\eta_{3}=-\frac{1}{60 m^{5}}\left[-4257-7270 m-4455 m^{2}-101 m^{3}-48 m^{4}-\right.$ $10 H_{3}\left(37+30 m+6 m^{2}\right)+30 H_{2}\left(60+75 m+31 m^{2}+4 m^{3}\right) c_{1}^{5}+10 m\left(1454+60 H_{3}+1548 m+21 H_{3} m+\right.$ $454 m^{2}+24 m^{3}-18 H_{2}\left(25+18 m+3 m^{2}\right) c_{1}^{3} c_{2}-30 m^{2}\left(234+3 H_{3}+118 m+8 m^{2}-2 H_{2}(24+\right.$ $7 m) c_{1}^{2} c_{3}-60 m^{2} c_{1}\left(141+2 H_{3}+67 m+4 m^{2}-2 H_{2}(15+4 m) c_{2}^{2}+2\left(-17+2 H_{2}-2 m\right) m c_{4}\right)-$ $120 m^{3}\left(-25+3 H_{2}-2 m\right) c_{2} c_{3}+2 m c_{5}+\left(\frac{1}{720 m^{6}}\right)\left(\left(102047+180 H_{2}^{2}+204435 m+187055 m^{2}+\right.\right.$ $81525 m^{3}+14738 m^{4}+600 m^{5}+40 H_{3}\left(389+498 m+214 m^{2}+30 m^{3}\right)-45 H_{2}(1223+2030 m+$ $\left.\left.1353 m^{2}+394 m^{3}+40 m^{4}\right)\right)-30 m\left(13629+22190 m+12915 m^{2}+2746 m^{3}+120 m^{4}+16 H_{3}(83+\right.$ $\left.\left.64 m+12 m^{2}\right)-6 H_{2}\left(1015+1209 m+470 m^{2}+56 m^{3}\right)\right)+120 m^{2}\left(2063+2088 m+589 m^{2}+30 m^{3}+\right.$ $\left.H_{3}(88+30 m)-18 H_{2}+\left(36+25 m+4 m^{2}\right)\right)+80 m^{2}\left(2323+2348 m+635 m^{2}+30 m^{3}+4 H_{3}(28+9 m)-\right.$ $\left.\left.3 H_{2}\left(259+173 m+26 m^{2}\right)\right)\right]+\left(-42+5 H_{2}-5 m\right) m c_{5}+20 m^{3}\left(\left(-473-8 H_{3}-195 m-10 m^{2}+\right.\right.$ $\left.12 \mathrm{H}_{2}(9+2 m)\right) c_{2} c_{3}+6 m\left(65-8 H_{2}+5 m\right) c_{2}+3 m\left(71-9 H_{2}+53\right) c_{10} m c_{6}$

Kembangan siri Taylor bagi fungsi pemberat $L_{f}(s, u)$ pada titik asalan adalah seperti berikut:

$$
L(s, u)=L_{00}+s L_{10}+u L_{01}+s u L_{11}+\frac{s^{2}}{2 !} L_{20}
$$

yang $L_{i, j}=\left.\frac{1}{i ! j !} \frac{\partial^{i+j}}{\partial s^{i} \partial u^{j}} L(s, u)\right|_{(0,0)}$. Dengan menggunakan persamaan (13) sehingga persamaan (24) pada skema lelaran (9), maka kita akan memperoleh

$$
e_{n+1}=\rho_{2} e_{n}^{2}+\rho_{3} e_{n}^{3}+\rho_{4} e_{n}^{4}+\rho_{5} e_{n}^{5}+\rho_{6} e_{n}^{6}+\rho_{7} e_{n}^{7}+O\left(e_{n}^{8}\right)
$$

yang nilai pekali $\rho_{i}(2 \leq i \leq 7)$ bergantung kepada $m$ dan parameter $L_{i, j}$. Bagi mencapai peringkat penumpuan lima, kita perlu menggantikan $L_{00}=0$ dan $L_{10}=1$ dan akan memperoleh

$e_{n+1}=\frac{\left(\left(-2+L_{01}\right) c_{1}^{2}\left(-9+H_{2}-m\right) c_{1}^{2}+2 m c_{2}\right)}{2 m^{4}} e_{n}^{5}+\rho_{6} e_{n}^{6}+\rho_{7} e_{n}^{7}+O\left(e_{n}^{8}\right)$

yang pekali $\rho_{6}$ dan $\rho_{7}$ bergantung kepada $m$ dan parameter $L_{i, j}$. Bagi mencapai peringkat penumpuan lapan, kita perlu menghadkan dengan mengambil nilai parameter seperti berikut:

$$
H_{2}=-2, H_{3}=36, L_{00}=0, L_{10}=1, L_{01}=2, L_{20}=2, L_{11}=4
$$

Dan ini akan menunjukkan kepada ralat berikut:

$$
\begin{aligned}
e_{n+1}= & \frac{1}{24 m^{7}}\left[c _ { 1 } ( c _ { 1 } ^ { 2 } ( 1 1 + m ) - 2 m c _ { 2 } ) \left(\left(677+108 m+7 m^{2}\right) c_{1}^{4}-24 m(9+m) c_{1}^{2} c_{2}\right.\right. \\
& \left.\left.+12 m^{2} c_{2}^{2}+12 m^{2} c_{1} c_{3}\right)\right] e_{n}^{8}+O\left(e_{n}^{9}\right)
\end{aligned}
$$

Persamaan ralat (28) menunjukkan bahawa penumpuan skema lelaran (9) mencapai pada peringkat penumpuan lapan dengan menggunakan tiga tahap dan empat penilaian fungsi pada setiap lelaran, iaitu $f\left(x_{n}\right), f\left[x_{n}, z_{n}\right], f\left(w_{n}\right)$ dan $f\left(y_{n}\right)$

\section{KASUS KHAS BAGI FUNGSI PEMBERAT}

Berdasarkan kaedah lelaran asal yang dibangunkan oleh Akram et al. (2019), tiga kasus khas telah dibincangkan bagi menentukan fungsi pemberat dalam kaedah lelarannya.

Kasus 1 Fungsi pemberat berbentuk polinomial berdasarkan kepada persamaan (10) adalah seperti berikut:

$$
\begin{gathered}
H(t)=1+2 t-t^{2}+6 t^{3} \\
L(s, u)=s+2 u+4 s u+s^{2}
\end{gathered}
$$

Persamaan (29) digantikan kedalam skema lelaran (9) yang diwakili sebagai KAT-1:

$$
\begin{gathered}
w_{n}=x_{n}-m \cdot \frac{f\left(x_{n}\right)}{f\left[x_{n}, z_{n}\right]}, n \geq 0, \\
y_{n}=w_{n}-m \cdot t \cdot\left(1+2 t-t^{2}+6 t^{3}\right) \cdot \frac{f\left(x_{n}\right)}{f\left[x_{n}, z_{n}\right]}, \\
x_{n+1}=y_{n}-m \cdot t \cdot\left(s+2 u+4 s u+s^{2}\right) \cdot \frac{f\left(x_{n}\right)}{f\left[x_{n}, z_{n}\right]}, \\
\text { yang } t=\sqrt[m]{\frac{f\left(w_{n}\right)}{f\left(x_{n}\right)}}, s=\sqrt[m]{\frac{f\left(y_{n}\right)}{f\left(w_{n}\right)}}, u=\sqrt[m]{\frac{f\left(y_{n}\right)}{f\left(x_{n}\right)}}
\end{gathered}
$$

Kasus 2 Fungsi pemberat dibangunkan dalam bentuk fungsi nisbah yang memenuhi persamaan (10) adalah seperti berikut:

$$
\begin{aligned}
H(t) & =\frac{1+8 t+11 t^{2}}{1+6 t} \\
L(s, u) & =s+2 u+4 s u+s^{2}
\end{aligned}
$$

Persamaan (31) digunakan pada kaedah lelaran yang diubah suai (9) yang diwakili sebagai KAT-2:

$$
\begin{gathered}
w_{n}=x_{n}-m \cdot \frac{f\left(x_{n}\right)}{f\left[x_{n}, z_{n}\right]}, n \geq 0, \\
y_{n}=w_{n}-m \cdot t \cdot\left(\frac{1+8 t+11 t^{2}}{1+6 t}\right) \cdot \frac{f\left(x_{n}\right)}{f\left[x_{n}, z_{n}\right]}, \\
x_{n+1}=y_{n}-m \cdot t \cdot\left(s+2 u+4 s u+s^{2}\right) \cdot \frac{f\left(x_{n}\right)}{f\left[x_{n}, z_{n}\right]},
\end{gathered}
$$

yang $t=\sqrt[m]{\frac{f\left(w_{n}\right)}{f\left(x_{n}\right)}}, s=\sqrt[m]{\frac{f\left(y_{n}\right)}{f\left(w_{n}\right)}}, u=\sqrt[m]{\frac{f\left(y_{n}\right)}{f\left(x_{n}\right)}}$ 
Kasus 3 Fungsi pemberat dibangunkan dengan menggunakan konsep trigonometri dan fungsi tersebut adalah seperti berikut:

$$
\begin{aligned}
H(t) & =\frac{5+18 t}{5+8 t-11 t^{2}} \\
L(s, u) & =s+2 u+4 s u+s^{2}
\end{aligned}
$$

Persamaan (33) digunakan pada kaedah lelaran diubah suai (9) dan diwakili sebagai KAT-3:

$$
\begin{aligned}
& w_{n}=x_{n}-m \cdot \frac{f\left(x_{n}\right)}{f\left[x_{n}, z_{n}\right]}, n \geq 0, \\
& y_{n}=w_{n}-m \cdot t \cdot\left(\frac{5+18 t}{5+8 t-11 t^{2}}\right) \cdot \frac{f\left(x_{n}\right)}{f\left[x_{n}, z_{n}\right]}, \\
& x_{n+1}=y_{n}-m \cdot t \cdot\left(s+2 u+4 s u+s^{2}\right) \cdot \frac{f\left(x_{n}\right)}{f\left[x_{n}, z_{n}\right]}, \\
& \text { yang } t=\sqrt[m]{\frac{f\left(w_{n}\right)}{f\left(x_{n}\right)}}, s=\sqrt[m]{\frac{f\left(y_{n}\right)}{f\left(w_{n}\right)}}, u=\sqrt[m]{\frac{f\left(y_{n}\right)}{f\left(x_{n}\right)}}
\end{aligned}
$$

\section{PENGUJIAN BERANGKA}

Dalam bahagian ini, kami akan melakukan ujian terhadap kaedah lelaran yang diubah suai daripada Akram et al. (2019) dengan menggunakan beberapa contoh yang terdiri daripada fungsi dengan punca mudah dan fungsi dengan punca berganda. Ujian ini dilakukan dengan menggunakan perisian Maple 18 dengan menggunakan kejituan pada digit keertian 3000. Perbandingan akan dilakukan terhadap kaedah lelaran peringkat lapan oleh Akram et al. (2019), Behl et al. (2018), Sharma et al. (2019) dan Zafar et al. (2018) bagi melihat ralat reja, $\left|x_{n+1}-x_{n}\right|$ dan peringkat penumpuan bagi setiap lelaran tersebut dengan menggunakan rumus daripada Cordero dan Torregrosa (2007),

$$
\mathrm{COC} \approx \frac{\ln \left(\left|x_{k+1}-x_{k}\right| /\left|x_{k}-x_{k-1}\right|\right)}{\ln \left(\left|x_{k}-x_{k-1}\right| /\left|x_{k-1}-x_{k-2}\right|\right)}
$$

Kaedah yang diperkenalkan oleh Akram et al. (2019) pada persamaan bagi kasus 1, kasus 2 dan kasus 3 diwakilkan masing-masing sebagai KA-1, KA-2 dan KA-3. Kaedah yang diubah suai pada persamaan (30), persamaan (32) dan persamaan (34) diwakilkan masingmasing sebagai KAT-1, KAT-2 dan KAT-3. Kami juga mewakilkan kaedah yang dibangunkan oleh Sharma et al. (2019) pada skema lelaran (5) sebagai KS.

Kami memilih kaedah yang dibangunkan oleh Zafar et al. (2018) dalam membandingkan kaedah yang dibangunkan. Skema lelaran yang dipilih adalah seperti berikut dan diwakilkan sebagai KZ,

$$
\begin{gathered}
y_{n}=x_{n}-m \frac{f\left(x_{n}\right)}{f^{\prime}\left(x_{n}\right)}, \\
z_{n}=y_{n}-m u_{n}\left(6 u_{n}^{3}-u_{n}^{2}+2 u_{n}+1\right) \frac{f\left(x_{n}\right)}{f^{\prime}\left(x_{n}\right)}, \\
x_{n+1}=z_{n}-m u_{n} t_{n}\left(1+2 u_{n}\right)\left(1+t_{n}\right)\left(1+2 w_{n}\right) \frac{f\left(x_{n}\right)}{f^{\prime}\left(x_{n}\right)} . \\
\text { dengan } u_{n}=\left(\frac{f\left(y_{n}\right)}{f\left(x_{n}\right)}\right)^{\frac{1}{m}}, w_{n}=\left(\frac{f\left(z_{n}\right)}{f\left(y_{n}\right)}\right)^{\frac{1}{m}} \text { dan } t_{n}=\left(\frac{f\left(z_{n}\right)}{f\left(x_{n}\right)}\right)^{\frac{1}{m}}
\end{gathered}
$$

\begin{tabular}{|c|c|c|}
\hline Fungsi untuk diuji & Nilai sebenar $\alpha$ & Kegandaan $m$ \\
\hline$f_{1}(x)=\tan ^{-1}\left(e^{x+2}+1\right)+\tanh \left(e^{-x \cos (x)}\right)-\sin (\pi x)$ & $-3.6323572 \ldots$ & 1 \\
\hline$f_{2}(x)=(\cos x-x)^{3}$ & $0.7390851332 \ldots$ & 3 \\
\hline$f_{3}(x)=\left((x-1)^{3}-1\right)^{50}$ & 2.0 & 50 \\
\hline$f_{4}(x)=\left(e^{-x}+2 \sin (x)\right)^{4}(x-2)^{3}$ & $3.162748871 \ldots$ & 4 \\
\hline$f_{5}(x)=\left(8 x e^{-x^{2}}-2 x-3\right)^{8}$ & $-1.7903531791 \ldots$ & 8 \\
\hline$f_{6}(x)=x^{3}-5.22 x^{2}+9.0825 x-5.2675$ & 1.75 & 2 \\
\hline$f_{7}(x)=(\ln (x)+\sqrt{x}-5)^{4}$ & $8.309432694 \ldots$ & 4 \\
\hline
\end{tabular}

Selain itu, kaedah yang dibangunkan oleh Behl et al. (2018) juga turut dibandingkan dengan mengambil skema lelaran:

$$
\begin{aligned}
& y_{n}=x_{n}-m \frac{f\left(x_{n}\right)}{f^{\prime}\left(x_{n}\right)}, \\
& z_{n}=y_{n}-\left(m+2 h_{n} m+\frac{1}{2} h_{n}^{2}(4 m+2 m)\right) \frac{f\left(x_{n}\right)}{f^{\prime}\left(x_{n}\right)} u_{n}, \\
& x_{n+1}=z_{n}-\left(m+m t_{n}+3 m h_{n}^{2}+m h_{n}\left(2+4 t_{n}+h_{n}\right)\right) \frac{f\left(x_{n}\right)}{f^{\prime}\left(x_{n}\right)} u_{n} t_{n} \\
& \text { Dengan } u_{n}=\left(\frac{f\left(y_{n}\right)}{f\left(x_{n}\right)}\right)^{\frac{1}{m}}, h_{n}=\frac{u_{n}}{1+u_{n}} \text { dan } t_{n}=\left(\frac{f\left(z_{n}\right)}{f\left(y_{n}\right)}\right)^{\frac{1}{m}} .
\end{aligned}
$$

Skema lelaran ini diwakilkan sebagai KB.

Senarai fungsi yang akan digunakan dalam menguji kaedah-kaedah tersebut terdapat pada Jadual 1.

JADUAL 1. Fungsi untuk diuji 
JADUAL 2. Perbandingan hasil kaedah lelaran pada fungsi $f_{1}$ dengan nilai awal $x_{0}=-3.9$

\begin{tabular}{|c|c|c|c|c|}
\hline & $n=1$ & $\begin{array}{c}x_{n+1}-x_{n} \\
n=2\end{array}$ & $n=3$ & $\mathrm{COC}$ \\
\hline KAT-1 & $1.58(-3)$ & $1.60(-16)$ & $2.07(-120)$ & 8.00 \\
\hline KAT-2 & $1.58(-3)$ & $7.88(-17)$ & $3.33(-123)$ & 8.00 \\
\hline KAT-3 & $1.58(-3)$ & $1.33(-16)$ & $3.86(-121)$ & 8.00 \\
\hline KA-1 & $4.59(-3)$ & $6.51(-13)$ & $1.54(-91)$ & 7.98 \\
\hline KA-2 & $4.54(-3)$ & $3.19(-13)$ & $2.43(-94)$ & 7.99 \\
\hline KA-3 & $4.57(-3)$ & $5.28(-13)$ & $2.40(-92)$ & 7.98 \\
\hline KB & $4.54(-3)$ & $2.89(-13)$ & $9.85(-95)$ & 7.99 \\
\hline $\mathrm{KZ}$ & $3.92(-3)$ & $1.26(-13)$ & $1.89(-97)$ & 7.99 \\
\hline KS & PM & $\mathrm{PM}$ & PM & - \\
\hline
\end{tabular}

JADUAL 3. Perbandingan hasil kaedah lelaran pada fungsi $f_{2}$ dengan nilai awal $x_{0}=1.0$

\begin{tabular}{|c|c|c|c|c|}
\hline & $n=1$ & $\begin{array}{c}x_{n+1}-x_{n} \\
n=2\end{array}$ & $n=3$ & $\mathrm{COC}$ \\
\hline KAT-1 & $6.29(-8)$ & $4.33(-60)$ & $2.20(-477)$ & 8.00 \\
\hline KAT-2 & $5.27(-8)$ & $6.45(-61)$ & $3.27(-484)$ & 8.00 \\
\hline KAT-3 & $5.92(-8)$ & $2.33(-60)$ & $1.33(-479)$ & 8.00 \\
\hline KA-1 & $2.34(-7)$ & $1.30(-53)$ & $1.20(-423)$ & 8.00 \\
\hline KA-2 & $1.21(-7)$ & $2.21(-56)$ & $2.67(-446)$ & 8.00 \\
\hline KA-3 & $1.91(-7)$ & $2.00(-54)$ & $2.88(-430)$ & 8.00 \\
\hline KB & $5.16(-8)$ & $4.92(-61)$ & $3.36(-485)$ & 8.00 \\
\hline $\mathrm{KZ}$ & $4.91(-8)$ & $4.06(-61)$ & $8.99(-486)$ & 8.00 \\
\hline KS & $1.12(0)$ & $2.55(-1)$ & $6.56(-2)$ & 0.92 \\
\hline
\end{tabular}


JADUAL 4. Perbandingan hasil kaedah lelaran pada fungsi $f_{3}$ dengan nilai awal $x_{0}=2.1$

\begin{tabular}{|c|c|c|c|c|}
\hline & \multicolumn{3}{|c|}{$\left|x_{n+1}-x_{n}\right|$} & \multirow{2}{*}{$\mathrm{COC}$} \\
\hline & $n=1$ & $n=2$ & $n=3$ & \\
\hline KAT-1 & $7.59(-7)$ & $3.71(-47)$ & $1.20(-369)$ & 8.00 \\
\hline KAT-2 & $4.86(-7)$ & $4.10(-49)$ & $1.07(-385)$ & 8.00 \\
\hline KAT-3 & $6.52(-7)$ & $8.83(-48)$ & $9.94(-375)$ & 8.00 \\
\hline KA-1 & $7.59(-7)$ & $3.71(-47)$ & $1.20(-369)$ & 8.00 \\
\hline KA-2 & $4.86(-7)$ & $4.10(-49)$ & $1.07(-385)$ & 8.00 \\
\hline KA-3 & $6.52(-7)$ & $8.83(-48)$ & $9.94(-375)$ & 8.00 \\
\hline KB & $4.65(-7)$ & $2.73(-49)$ & $3.79(-387)$ & 8.00 \\
\hline $\mathrm{KZ}$ & $4.78(-7)$ & $5.67(-49)$ & $2.22(-384)$ & 8.00 \\
\hline KS & $1.95(-6)$ & $5.92(-39)$ & $1.39(-266)$ & 7.00 \\
\hline
\end{tabular}

JADUAL 5. Perbandingan hasil kaedah lelaran pada fungsi $f_{4}$ dengan nilai awal $x_{0}=3.5$

\begin{tabular}{lcccc}
\hline & & $\left|x_{n+1}-x_{n}\right|$ & & COC \\
\cline { 2 - 4 } & $n=1$ & $n=2$ & $n=3$ & 7.99 \\
KAT-1 & $1.13(-2)$ & $4.15(-15)$ & $1.68(-144)$ & 7.99 \\
KAT-2 & $2.43(-2)$ & $9.49(-13)$ & $6.84(-96)$ & 7.98 \\
KAT-3 & $2.32(-2)$ & $9.64(-13)$ & $1.22(-95)$ & 8.00 \\
KA-1 & $4.37(-5)$ & $2.56(-34)$ & $3.49(-268)$ & 8.00 \\
KA-2 & $3.95(-5)$ & $6.10(-35)$ & $2.00(-273)$ & 8.00 \\
KA-3 & $4.20(-5)$ & $1.58(-34)$ & $6.28(-270)$ & 8.00 \\
KB & $3.85(-5)$ & $4.50(-35)$ & $1.57(-274)$ & 8.00 \\
KZ & $3.28(-5)$ & $1.70(-35)$ & $8.80(-278)$ & $* 6.97$ \\
KS & $1.18(-1)$ & $1.42(-2)$ & $2.69(-13)$ & \\
\hline
\end{tabular}

*penumpuan pada lelaran 4

JADUAL 6. Perbandingan hasil kaedah lelaran pada fungsi $f_{5}$ dengan nilai awal $x_{0}=-1.6$

\begin{tabular}{lcccc}
\hline & \multicolumn{3}{c}{$\left|x_{n+1}-x_{n}\right|$} & \multirow{2}{*}{ COC } \\
\cline { 2 - 3 } & $n=1$ & $n=2$ & $1.80(-363)$ & 8.00 \\
KAT-1 & $1.82(-6)$ & $3.91(-46)$ & $2.92(-373)$ & 8.00 \\
KAT-2 & $1.50(-6)$ & $2.69(-47)$ & $1.69(-362)$ & 8.00 \\
KAT-3 & $1.95(-6)$ & $5.34(-46)$ & $4.48(-369)$ & 8.00 \\
KA-1 & $1.49(-6)$ & $7.80(-47)$ & $8.22(-386)$ & 8.00 \\
KA-3 & $9.53(-7)$ & $7.26(-49)$ & $3.00(-374)$ & 8.00 \\
KB & $1.28(-6)$ & $1.81(-47)$ & $1.43(-386)$ & 8.00 \\
KZ & $9.29(-7)$ & $5.85(-49)$ & $1.18(-384)$ & 8.00 \\
KS & $9.13(-7)$ & $9.39(-49)$ & $3.19(-22)$ & $* 7.00$ \\
\hline
\end{tabular}

*penumpuan pada lelaran 4 
JADUAL 7. Perbandingan hasil kaedah lelaran pada fungsi $f_{6}$ dengan nilai awal $x_{0}=1.8$

\begin{tabular}{lcccc}
\hline & & $\left|x_{n+1}-x_{n}\right|$ & & COC \\
\cline { 2 - 4 } & $n=1$ & $n=2$ & $n=3$ & 7.99 \\
KAT-1 & $4.66(-4)$ & $3.24(-16)$ & $2.17(-113)$ & 7.99 \\
KAT-2 & $4.56(-4)$ & $1.53(-16)$ & $2.84(-116)$ & 7.99 \\
KAT-3 & $4.62(-4)$ & $2.58(-16)$ & $2.92(-114)$ & 7.99 \\
KA-2 & $4.66(-4)$ & $3.24(-16)$ & $2.17(-113)$ & 7.99 \\
KA-3 & $4.56(-4)$ & $1.53(-16)$ & $2.84(-116)$ & 7.99 \\
KB & $4.62(-4)$ & $2.58(-16)$ & $2.92(-114)$ & 8.00 \\
KZ & $4.53(-4)$ & $1.31(-16)$ & $7.40(-117)$ & 7.99 \\
KS & $3.88(-4)$ & $5.16(-17)$ & $5.93(-120)$ & 2.66 \\
\hline
\end{tabular}

JADUAL 8. Perbandingan hasil kaedah lelaran pada fungsi $f_{6}$ dengan nilai awal $x_{0}=9.0$

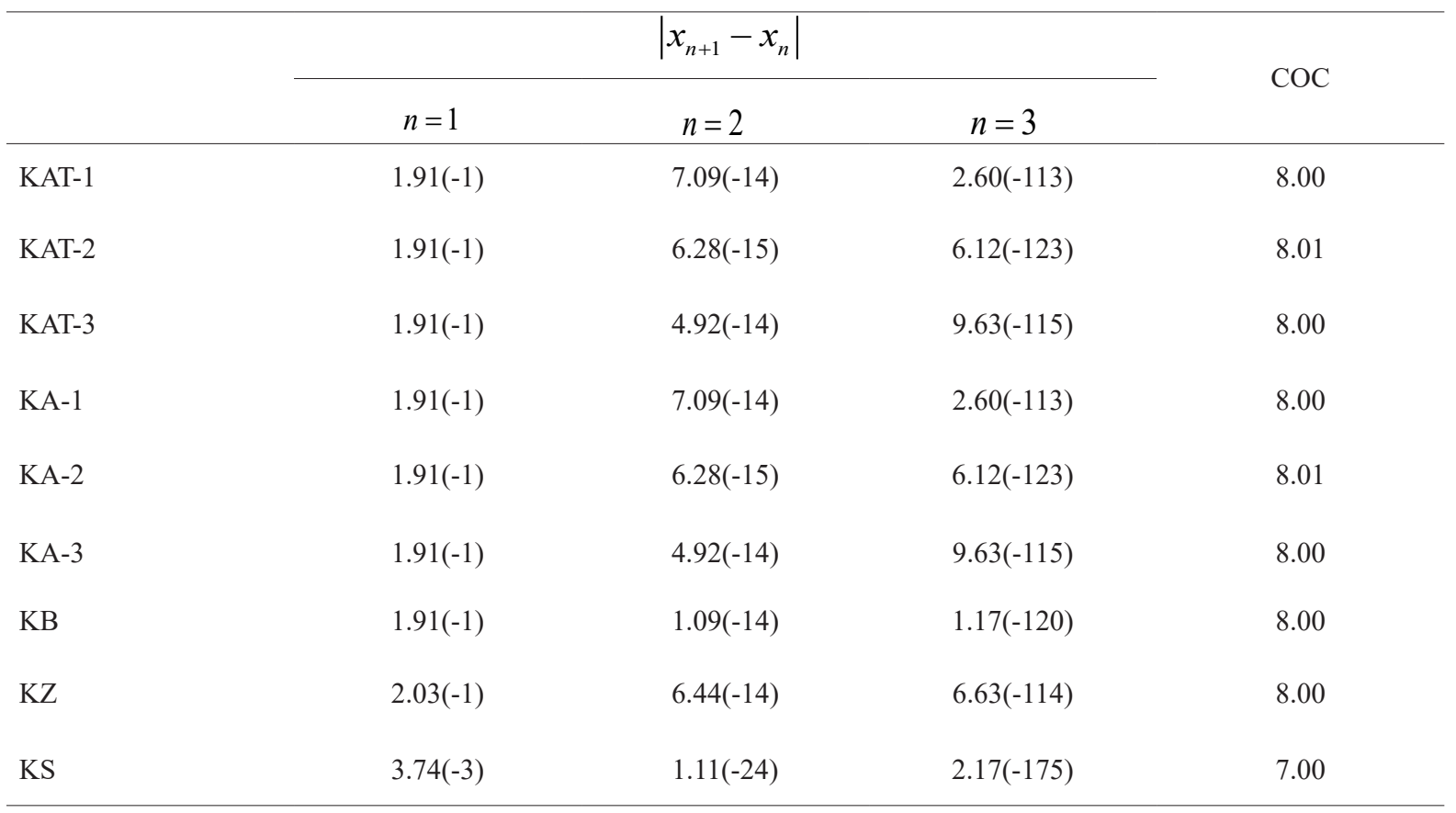

Hasil ujian yang dilakukan mendapati bahawa kaedah lelaran yang dibangunkan oleh Akram et al. (2019) dan kaedah lelaran terubah suai daripada segi ketiadaan sebarang terbitan memberikan hasil yang hampir sama dan mencapai pada tahap penumpuan yang optimal. Kaedah yang diubah suai juga dapat bersaing dengan kaedah yang diperkenalkan oleh Sharma et al. (2019). Kelebihan kepada kaedah yang diubah suai 
ialah ia bebas daripada sebarang terbitan dan ini dapat mengurangkan penilaian fungsi yang perlu dilakukan. Walau bagaimanapun, kaedah Steffensen terlalu sensitif pada anggaran nilai awal yang dipilih dan mencapah apabila nilai awal yang diambil tidak mendekati nilai punca yang ingin dicari (Jadual 2-8).

\section{KESIMPULAN}

Dalam kajian ini, kami mencadangkan pengubahsuaian terhadap skema lelaran asal yang mempunyai terbitan oleh Akram et al. (2019) kepada skema lelaran yang bebas daripada sebarang terbitan dengan menggunakan konsep beza terhingga dan kaedah Steffensen. Kaedah ini juga telah mencapai peringkat penumpuan optimal menurut konjektur Kung-Traub. Selain itu, skema lelaran yang diubah suai juga telah mendapat nilai Indeks Keberkesanan, $E=\sqrt[4]{8} \approx 1.682$ dan skema lelaran ini lebih baik daripada kaedah Newton Klasik, $E=\sqrt{2} \approx 1.414$. Maka, skema lelaran yang dibangunkan ini dapat menyelesaikan persamaan tak linear dalam mencari punca berganda dan juga punca mudah yang mencapai pada peringkat penumpuan optimal lapan. Skema yang diutarakan dalam makalah ini boleh dikembangkan lagi untuk menyelesaikan sistem persamaan tak linear seperti yang sering ditemui dalam membina kaedah baharu bagi menyelesaikan persamaan terbitan (Ibrahim et al. 2019; Ismail et al. 2016; Jikantoro et al. 2015;). Sangat menarik juga sekiranya skema yang dicadangkan dapat diadaptasi kepada penyelesaian persamaan tak linear dalam medan selain medan nombor nyata seperti yang dikaji oleh Saburov dan Khameini Ahmad (2015).

\section{PENGHARGAAN}

Penghargaan diberikan kepada Universiti Kebangsaan Malaysia untuk geran penyelidikan (GUP-2019-033) untuk pembiayaan kewangan kajian ini.

\section{RUJUKAN}

Akram, S., Zafar, F. \& Yasmin, N. 2019. An optimal eighthorder family of iterative methods for multiple roots. Mathematics 7(8): 672.

Behl, R., González, D., Maroju, P. \& Motsa, S.S. 2018. An optimal and efficient general eighth-order derivative free scheme for simple roots. Journal of Computational and Applied Mathematics 330: 666-675.

Behl, R., Martínez, E., Cevallos, F. \& Alarcón, D. 2019a. A higher order Chebyshev-Halley-type family of iterative methods for multiple roots. Mathematics 7(4): 339.

Behl, R., Salimi, M., Ferrara, M., Sharifi, S. \& Alharbi, S.K. 2019b. Some real-life applications of a newly constructed derivative free iterative scheme. Symmetry 11(2): 239.

Cordero, A. \& Torregrosa, J.R. 2016. On the design of optimal iterative methods for solving nonlinear equations. In Advances in Iterative Methods for Nonlinear Equations. Cham: Springer. hlm. 79-111.
Cordero, A. \& Torregrosa, J.R. 2015. Low-complexity rootfinding iteration functions with no derivatives of any order of convergence. Journal of Computational and Applied Mathematics 275: 502-515.

Cordero, A. \& Torregrosa, J.R. 2007. Variants of Newton's method using fifth-order quadrature formulas. Applied Mathematics and Computation 190(1): 686-698.

Cordero, A., Hueso, J.L., Martínez, E. \& Torregrosa, J.R. 2013. A new technique to obtain derivative-free optimal iterative methods for solving nonlinear equations. Journal of Computational and Applied Mathematics 252: 95-102.

Ibrahim, Z.B., Zainuddin, N., Othman, K.I., Suleiman, M. \& Zawawi, I.S.M. 2019. Variable order block method for solving second order ordinary differential equations. Sains Malaysiana 48(8): 1761-1769.

Ismail, F., Hussain, K. \& Senu, N. 2016. A sixth-order RKFD method with four-stage for directly solving special fourth-order ODEs. Sains Malaysiana 45(11): 1747-1754.

Jikantoro, Y.D., Ismail, F. \& Senu, N. 2015. Zero-dissipative trigonometrically fitted hybrid method for numerical solution of oscillatory problems. Sains Malaysiana 44(3): 473-482.

Junjua, M.U.D., Zafar, F. \& Yasmin, N. 2019. Optimal derivative-free root finding methods based on inverse interpolation. Mathematics 7(2): 164.

Kung, H.T. \& Traub, J.F. 1974. Optimal order of one-point and multipoint iteration. Journal of the ACM 21(4): 643-651.

Li, J., Wang, X. \& Madhu, K. 2019. Higher-order derivativefree iterative methods for solving nonlinear equations and their basins of attraction. Mathematics 7(11): 1052.

Ostrowski, A.M. 1966. Solution of Equations and Systems of Equations: Pure and Applied Mathematics: A Series of Monographs and Textbooks. Massachusettes: Academic Press.

Parvaneh, F. \& Ghanbari, B. 2017. A third order method for solving nonlinear equations. Chiang Mai Journal of Science 44(3): 1154-1162

Petković, M.S. \& Petković, L.D. 2019. Construction and efficiency of multipoint root-ratio methods for finding multiple zeros. Journal of Computational and Applied Mathematics 351: 54-65.

Saburov, M. \& Khameini Ahmad, M.A. 2015. The number of solutions of cubic equations over $\mathrm{Q}_{3}$. Sains Malaysiana 44(5): 765-769.

Schröder, E. 1870. Über unendlich viele Algorithmen zur Auflösung der Gleichungen Mathematische Annalen 2(2): 317-365.

Sharma, J.R., Kumar, D. \& Argyros, I.K. 2019. An efficient class of Traub-Steffensen-like seventh order multiple-root solvers with applications. Symmetry 11(4): 518.

Steffensen, J.F. 1933. Remarks on iteration. Scandinavian Actuarial Journal 1933(1): 64-72.

Tao, Y. \& Madhu, K. 2019. Optimal fourth, eighth and sixteenth order methods by using divided difference techniques and their basins of attraction and its application. Mathematics 7(4): 322.

Zafar, F., Cordero, A. \& Torregrosa, J.R. 2018. An efficient family of optimal eighth-order multiple root finders. Mathematics 6(12): 310 . 
Jabatan Sains Matematik

Fakulti Sains dan Teknologi

Universiti Kebangsaan Malaysia

43600 UKM Bangi, Selangor Darul Ehsan

Malaysia
*Pengarang untuk surat-menyurat; email: ishak_h@ukm.edu.my

Diserahkan: 24 Mac 2020

Diterima: 10 April 2020 